\title{
Estudo da capacidade de carga em trilha no Parque Estadual da Mata do Limoeiro, Itabira (MG)
}

\section{Study of the Carrying Capacity on track in the State Park of Mata do Limoeiro, Itabira (MG, Brazil)}

\author{
Amanda Costa de Oliveira, Ana Cecília Gomes de Paula, \\ Clarisse Carvalho Miranda, Gabriel Henrique Soares Almeida, \\ Edson Maurício Marques Ferrari, Bianca Cabral Caldeira
}

\begin{abstract}
RESUMO: As Unidades de Conservação (UCs) detêm papel fundamental na proteção e preservação do meio ambiente e da biodiversidade local. Para a conservação destas áreas, é necessário adequar os atrativos e as atividades promovidas à gestão dos recursos nas unidades, principalmente aquelas voltadas ao uso público. Com o presente trabalho, visa-se elaborar o estudo de capacidade da trilha da Gruta do Limoeiro, adequando a gestão de recursos locais às atividades de uso público, sem comprometer a capacidade de suporte da trilha. Este artigo determinou a capacidade de carga da trilha da Gruta do Limoeiro pertencente ao Parque Estadual Mata do Limoeiro (PEML), a fim de garantir o manejo adequado da trilha, evitando o seu comprometimento físico. A partir da capacidade de carga, foi determinada a quantidade de visitantes ideal para a trilha por meio de cálculos baseados na metodologia descrita por Cifuentes (1992) e na adaptação feita por Cordeiro, Körössy e Selva (2013). Foi obtido o limite total de 1056 visitantes de maneira a não acarretar maiores impactos sobre a trilha da Gruta do Limoeiro.
\end{abstract}

PALAVRAS-CHAVE: Capacidade de Carga; Parque Estadual Mata do Limoeiro; Uso Público; Manejo de Recursos Naturais; Turismo Sustentável.

\begin{abstract}
Protected Areas have an important role in protecting and preserving the environment and local biodiversity. For the conservation of these areas, it is necessary to adjust the attractions and activities promoted to the management of resources, especially those aimed for public use. This article aims to develop the ability to study the Gruta do Limoeiro track, adapting the management of local resources to public use activities without compromising the track capacity. This article has determined the carrying capacity of Gruta do Limoeiro track belonging to the Mata do Limoeiro State Park in order to ensure proper management of the track, avoiding their physical compromising. The charge capacity was determined the number of visitors to the ideal path based on the method described by Cifuentes (1992) and adaptation made by Cordeiro, Körössy and Selva (2013). a total limit of 1056 visitors was obtained in order not to cause in order to not cause major impacts on the Gruta do Limoeiro track.
\end{abstract}

KEYWORDS: Carrying Capacity; Mata do Limoeiro State Park; Public Use; Natural Resource Management; Sustainable Tourism. 


\section{Introdução}

As Unidades de Conservação (UCs) surgiram a partir da necessidade de proteção das áreas naturais com características relevantes ao meio ambiente. O Sistema Nacional de Unidades de Conservação da Natureza (SNUC) as define como um espaço territorial e seus recursos ambientais, incluindo as águas jurisdicionais, com características naturais relevantes, com objetivos de conservação e limites definidos, aos quais se aplicam garantias adequadas de proteção (BRASIL, 2000).

O Parque Estadual Mata do Limoeiro (PEML), localizado no distrito de Ipoema pertencente ao município de Itabira - Minas Gerais, é classificado como uma Unidade de Conservação de proteção integral, que permite o uso indireto dos recursos naturais (BRASIL, 2000). O uso indireto da UC deve ser feito de modo sustentável, de forma a garantir que a conservação da área seja alcançada. $\mathrm{Na}$ garantia do uso sustentável podem ser incluídas atividades que permitam o uso de recursos sem comprometer suas funções ambientais, servindo de atrativo ao público, como as atividades do ecoturismo.

Dentre esses aspectos de uma Unidade de Conservação, as trilhas são um importante meio para a realização de atividades e eventos promovidos pelo Parque, pois possibilitam o contato direto dos visitantes com a natureza, a partir do acesso aos atrativos, como cachoeiras, grutas, além da fauna e flora local. Ressalta-se que a prática de ecoturismo tem aumentado, o que justifica que o uso desses espaços seja feito de maneira planejada, obedecendo o limite suportado pelos recursos ambientais locais, de forma a não os agredir.

Um dos mecanismos que contribui para a conservação das trilhas é o estudo de capacidade, que permite avaliar o grau de uso e determinar a quantidade de visitantes que a trilha suporta. As trilhas de visitação do PEML são acessadas sem que haja respaldo científico que indique a quantidade de visitantes pertinente a cada trilha. Sendo assim, visa-se adequar o Parque às atividades de visitação, visando também diminuir os efeitos adjacentes que a má gestão delas possa gerar.

Diante da ausência de estudos relacionados à capacidade de trilhas, procurou-se determinar a capacidade de carga da trilha da Gruta do Limoeiro pertencente ao PEML, a fim de contribuir cientificamente com estudos voltados à melhoria da gestão e do gerenciamento do Parque, em consonância com o meio ambiente. Além disso, busca-se a garantia do uso das trilhas sem comprometer sua capacidade e funções ambientais.

\section{Uso público, impactos da visitação e capacidade de carga}

O SNUC, criado pela Lei no 9.985 de 2000, é uma das principais políticas de gestão que define e classifica as Unidades de Conservação como áreas protegidas. Dentre suas premissas, está a de preservação da diversidade biológica e promoção do desenvolvimento sustentável, além de favorecendo condições para promover a educação e a interpretação 
ambiental, além do contato com a natureza (BRASIL, 2000). Neste contexto, o uso público nas UCs que permitem o uso indireto, desempenha importante papel para o alcance dos objetivos estabelecidos pelo SNUC, uma vez que aproxima a sociedade com 0 meio ambiente, proporcionando 0 desenvolvimento de pesquisas, educação ambiental, recreação, turismo e outras atividades (NELSON, 2012).

Não obstante, apesar de o uso indireto não ser uma atividade com grande impacto, quando realizada de forma não orientada por parte da gestão local, pode gerar danos ao meio onde são exercidas, como erosão do solo, estresse na fauna, além dos efeitos de borda na vegetação. Como descrito por Silva et al. (2009), "a carência de instruções e de diretrizes definidas relacionadas ao público, são práticas comuns em UCs, estando coligadas a falta dessas informações nos Planos de Uso Público (PUP) e/ou Plano de Manejo (PM)". Estes documentos devem preceder a atividade do uso público (LEUZINGER, 2011), uma vez que orientam o zoneamento do território, o manejo dos recursos naturais, além de que estabelecem as normas que devem presidir o uso da área (BRASIL, 2000).

O ecoturismo é um dos seguimentos do turismo que promove a valorização da biodiversidade e preza pela preservação do Patrimônio Natural (FONSECA FILHO; RIBEIRO, 2016). Aspectos positivos são coligados a prática, tais como a geração de empregos diretos e indiretos, promoção de práticas ecológicas, conhecimento da realidade local, servindo de atrativo turístico. Entretanto, a falta de planejamento pode ser prejudicial ao meio ambiente, devido à falta de diretrizes que suportem tais práticas na UC, podendo levar a impactos ambientais (LOBO, 2008). Ainda de acordo com os estudos realizados por Lobo (2008), turistas entrevistados no Parque Estadual Turístico do Alto Ribeira (PETAR), associam a prática de ecoturismo à preservação de algum recurso natural e conseguem assimilar tanto a geração de impactos negativos e positivos, tanto na UC quanto na comunidade local.

\section{O uso público por meio das trilhas interpretativas}

O uso público em Unidades de Conservação tem crescido por meio da modalidade do ecoturismo, uma vez que visitantes procuram ambientes naturais em função da melhor qualidade de vida, e fatores como apreciação da beleza natural das atrações locais. Neste sentido, as trilhas interpretativas são áreas que permitem a aproximação da comunidade e visitantes com o meio ambiente, o que proporciona o conhecimento do local visitado, como também o exercício da educação ambiental.

As trilhas são definidas como percurso em um sítio natural, as quais promovem o contato e o aprendizado mais estreito entre o ser humano e a natureza. São instrumentos educativos que possibilitam o conhecimento da fauna, flora, relevo, relações ecológicas do meio ambiente e sua proteção (GUILLAUNON, 1977; MENGHINI; GUERRA, 2008). As trilhas deixaram de ter apenas a concepção de suprir a necessidade de deslocamento do ser humano e ganharam a função educativa e interpretativa de proporcionar e familiarizar o contato com a natureza (CAMPOS, 2006). 


\section{Impactos ambientais inerentes às trilhas}

Dos impactos ambientais inerentes à prática de uso público em trilhas, devem ser considerados os seguintes aspectos:

- Impacto sobre o solo: advindo da compactação, reduz a capacidade de infiltração da água e aumenta os processos erosivos. A compactação do solo é um dos principais impactos relacionados à utilização das trilhas e de suas imediações (FIGUEIREDO et al., 2010);

- Impacto direto e indireto sobre a flora: impacto mecânico na vegetação, introdução de espécies exóticas e efeito de borda na trilha, podendo ocorrer casos de extinção de espécies (PONTES; MELLO, 2013);

- Impactos sobre a fauna: acarretam mudanças no comportamento faunístico, como a sua migração, conforme apontado por Leuzinger (2011), além de causar estresse nos animais.

Os impactos de uso público nas trilhas podem ser minimizados caso sejam avaliados e relacionados à capacidade de carga, além de estabelecer o grau de uso, sem provocar deterioração ambiental (SWARBROOKE, 1999). No presente artigo foi dado enfoque aos impactos somente sobre o solo, visto que a análise de capacidade de carga leva em consideração o uso do solo na metodologia aplicada.

\section{Estudo da Capacidade de Carga}

A capacidade de carga é definida como o nível máximo de uso que determinada área pode suportar, avaliando-se os fatores ligados ao meio ambiente (TAKAHASHI, 2004). Considerando sua importância, faz-se necessária a gestão das trilhas de visitação, bem como garantir sua abordagem no Plano de Manejo da UC. O planejamento, quando feito de maneira adequada, diminui significativamente os efeitos negativos da visitação, devendo ser considerada a sustentabilidade das trilhas por meio da determinação da sua capacidade de carga (SOUZA; MARTOS, 2008).

Devido ao impacto do uso público nas trilhas, o monitoramento das atividades desempenhadas também é imprescindível para a sustentabilidade da prática da visitação, sendo relevante o cálculo da capacidade de carga para evitar o desequilíbrio do local, conservar e proteger a biodiversidade (VIANA, 2008). Sendo assim, por meio do estudo da capacidade de carga será determinada a quantidade de pessoas que poderão usar a área, sem causar danos significativos ao meio. 


\section{Parque Estadual Mata do Limoeiro}

O Parque Estadual Mata do Limoeiro foi criado pelo Decreto de Lei oㅡ 45.566 em março de 2011 e está localizado em Ipoema, distrito do município de Itabira (MG). Abrange uma área de 2005,5 ha e é classificado como uma UC de proteção integral (MINAS GERAIS, 2011). A Figura 1 apresenta o mapa de localização da área de estudo e as trilhas de uso público da Unidade de Conservação.
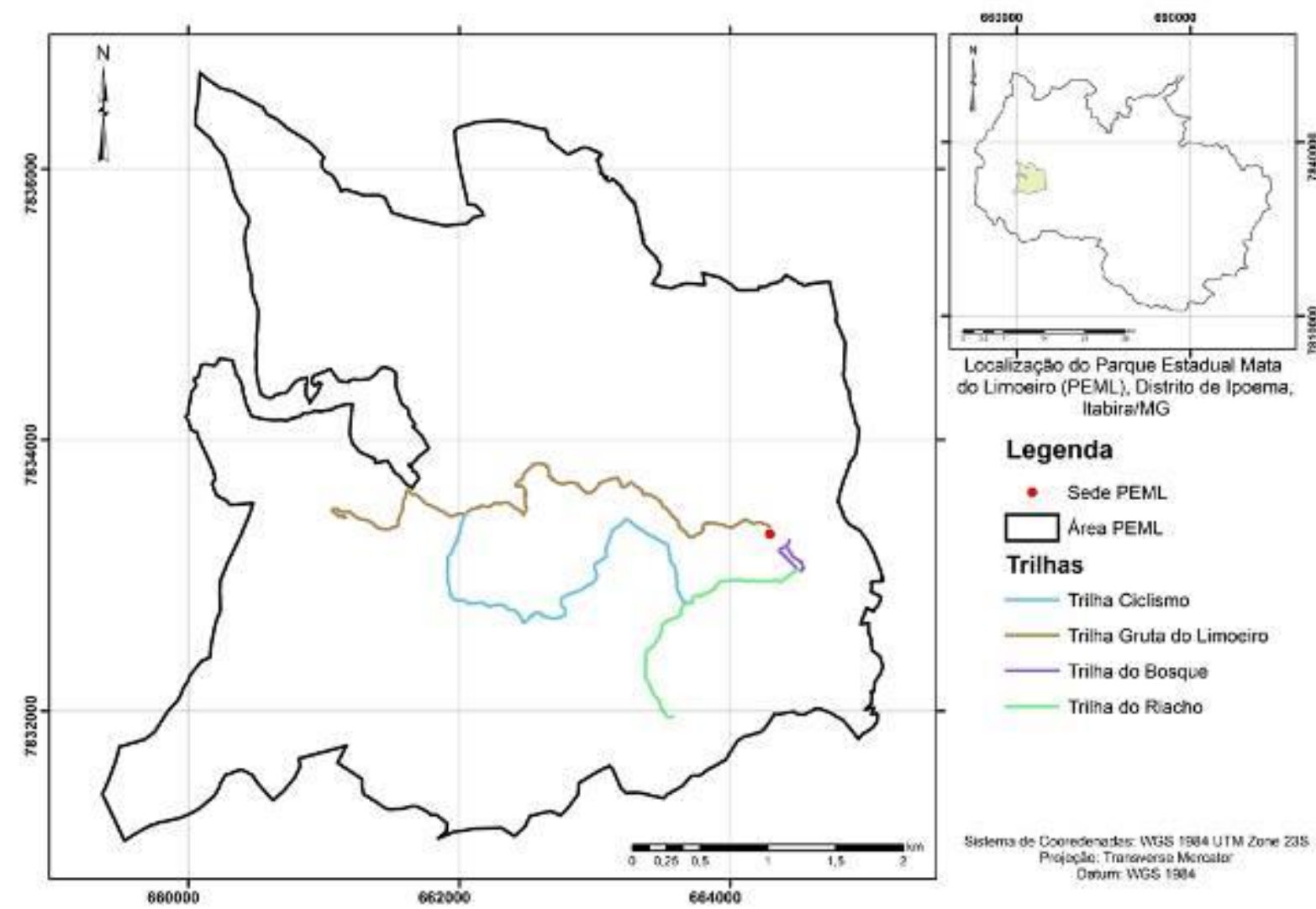

Figura 1: Localização do Parque Estadual Mata do Limoeiro. Fonte: Autores (2016). Figure 1: Location of State Park of Mata do Limoeiro. Source: Authors (2016).

A respeito da importância da biodiversidade local, predominam-se áreas de transição entre Cerrado e Mata Atlântica, que concentram espécies faunísticas e florísticas, sendo algumas ameaçadas de extinção, como a Alouatta sp. e Dallergia nigra, conhecidas popularmente como Bugio e Jacarandá Caviúna, respectivamente. A extensa fauna e flora agregam valor turístico, além dos atrativos naturais do PEML em si, como cachoeiras, lagoas, grutas, mirantes e trilhas (OLIVEIRA et al., 2015).

O Parque do Limoeiro possui grande relevância relacionada ao uso público externo devido à rica biodiversidade e aos atrativos naturais que despertam o interesse de visitantes pela UC, principalmente em finais de semana, feriados e épocas festivas, como o Carnaval. Ações são realizadas ao longo do ano, e contam com a interação das comunidades do entorno e visitantes, tais como Projeto Eco Folia, atividades comemorativas no 
aniversário Festejando o Parque, projetos no Natal e ações nos meses de junho e setembro, voltadas à Semana do Meio Ambiente e o Dia da Árvore, respectivamente (OLIVEIRA et al., 2015). Tais atrações desenvolvidas servem como atrativo e promoção ao ecoturismo.

O manejo e planejamento das atividades podem ser alcançados eficientemente a partir da criação de Planos de Uso Público, componente também previsto no Plano de Manejo de uma UC. O estudo da capacidade de carga das trilhas é uma ferramenta coligada ao PUP e contribui para garantir o seu uso sustentável. A determinação deste parâmetro no PEML é de grande relevância, visto que a UC recebe visitantes anualmente, atraídos por eventos promovidos na área. Dentre as atividades promovidas, estão caminhadas e ciclismo, atividades que alteram as propriedades do solo, principalmente sua compactação.

A capacidade de carga da trilha da Gruta do Limoeiro do PEML, representada pela Figura 1, foi determinada com intuito de quantificar 0 número de visitantes que a mesma pode suportar. A trilha apresenta trechos com cobertura arbórea e outros com ausência cobertura vegetal, serapilheira e solo pedregoso, sendo possível visualizar ao longo do trajeto a transição da Mata Atlântica para o Cerrado.

\section{Metodologia}

O estudo da capacidade de carga da trilha da Gruta do Limoeiro baseou-se na metodologia proposta por Cordeiro, Körössy e Selva (2013), uma adaptação da metodologia de Cifuentes (1992). Para a metologia adotada são definidas três categorias de capacidade de carga a serem consideradas para sua determinação: Capacidade de Carga Física (CCF), Capacidade de Carga Real (CCR) e Capacidade de Carga Efetiva (CCE).

O estudo foi respaldado por publicações científicas, consulta à gestão do Parque, relatórios, Plano de Manejo do PEML e levantamento em campo. A coleta de dados em campo, especificamente na trilha da Gruta do Limoeiro, ocorreu no dia 07 de novembro de 2015, sendo realizadas observações e medições, a fim de compor os dados da metodologia proposta. No estudo de capacidade da trilha foram coletados 113 pontos em 4,9 km de extensão da trilha, observando-se mudanças físicas e estruturais, como demonstram as Figuras 2 e 3 . Foram coletados dados da largura, comprimento e altitude, além de coordenadas geográficas, observação do estado de conservação e infraestrutura da trilha, características físicas, biológicas e as áreas de entorno. 

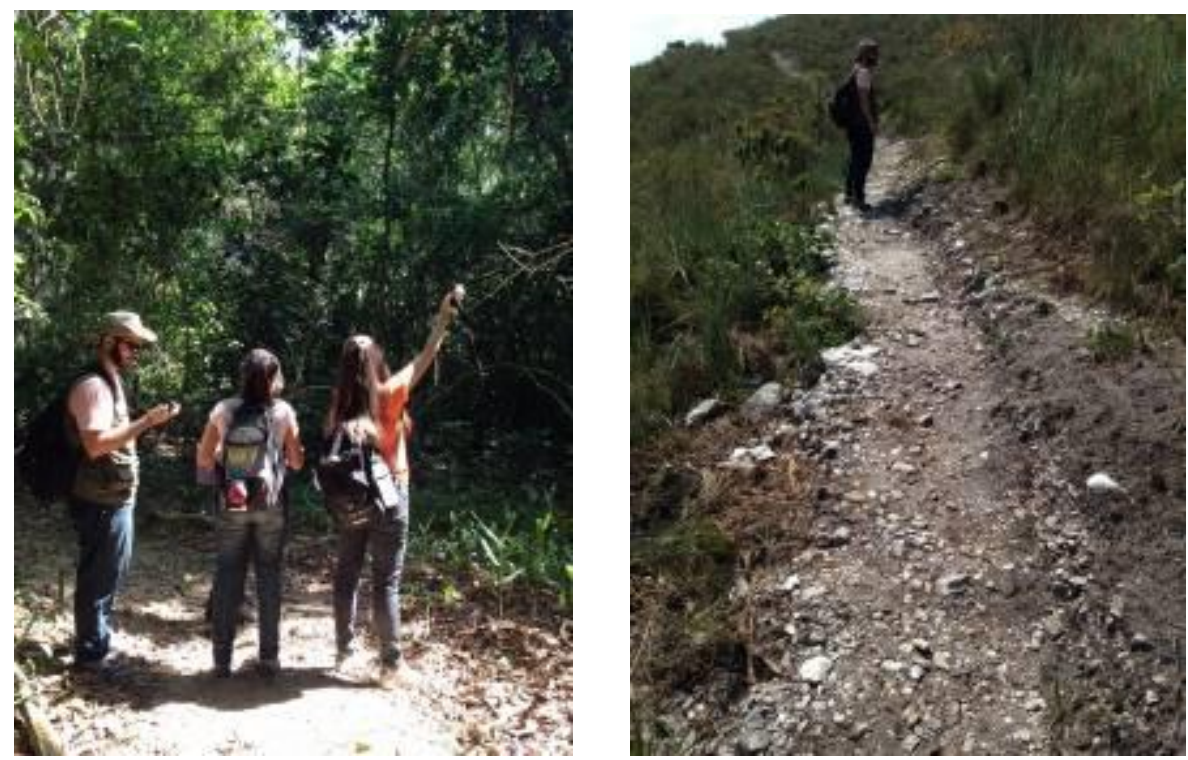

Figura 2 e 3: Coleta de dados em campo (esquerda). Observação das características físicas e biológicas da trilha da Gruta do Limoeiro (direita).

Fonte: Autores (2016).

Figure 2 and 3: Data colletion in situ (left). Observation of physical and biological carachteristics of Gruta do Limoeiro Trail (right). Source: Authors (2016)

\section{Capacidade de Carga Física}

A Capacidade de Carga Física (CCF) foi obtida a partir das medições feitas em campo, levando-se em consideração a área total da trilha e o tempo necessário para visitação, conforme a fórmula 1:

$$
C C F=\frac{\mathrm{s} * \mathrm{~T}}{s * t}
$$

Em que: $\mathrm{S}$ - superfície total da área visitada $\left(\mathrm{m}^{2}\right)$; $\mathrm{s}$ - espaço ocupado por cada visitante ( $\mathrm{m}^{2}$ por visitante); $\mathrm{T}$ - tempo total que a área está disponível à visitação (horas por dia) e $\mathrm{t}$ - tempo necessário para visitar a área (horas).

\section{Capacidade de Carga Real}

A CCF não é suficiente para determinar o máximo de visitantes que a área pode suportar, por isso, variáveis associadas às características físicas, biológicas, sociais, ambientais, de visitação e de manejo da trilha, devem ser consideradas. (CORDEIRO; KÖRÖSSY; SELVA, 2013). Essas, portanto, são identificadas por meio dos Fatores de Correção (FC), que consistem em condições impostas ao cálculo que alteram os resultados de forma a obtê-los o mais real possível. Sendo assim, a Capacidade de Carga Real (CCR) foi calculada de acordo com a expressão 2:

$$
F C=1-\frac{M l}{M t}
$$

Em que: Ml - magnitude limitante e Mt - magnitude total. 

obtém-se:

A partir dos cálculos do FC e da CCF, representado pela expressão 3,

$$
C C R=C C F=F C_{1} * F C_{2} * \ldots C_{n}
$$

Em que: $F_{n}$ - Fator de Correção de variável $n$.

De acordo com Cifuentes (1992), os FC variam conforme as particularidades do local de estudo. Relacionados ao turismo no interior de uma trilha, são comuns: a susceptibilidade do solo à erosão, a acessibilidade à área a ser visitada, as interferências das chuvas e dos períodos de sol intenso, os períodos em que o Parque fica fechado devido às manutenções, os períodos de reprodução e acasalamento de espécies sensíveis, dentre outros.

Com o levantamento de informações da trilha da Gruta do Limoeiro, foram identificados os principais Fatores de Correção que influenciam em sua visitação, os quais são: a erodibilidade ( $\left.F C_{1}\right)$, a acessibilidade $\left(F_{2}\right)$, a ausência de cobertura arbórea $\left(\mathrm{FC}_{3}\right)$, a precipitação $\left(\mathrm{FC}_{4}\right)$ e o alagamento $\left(\mathrm{FC}_{5}\right)$.

A erodibilidade, por comprometer a trilha devido aos riscos suscetíveis à erosão, interfere na qualidade do solo e em sua capacidade de infiltração da água. Sendo assim, possui níveis a serem determinados conforme o grau de risco de erosão. De acordo com Correia (2014), para calcular o FC da erodibilidade, devem ser consideradas as mudanças de aclives e declives, respeitando os três parâmetros de avaliação de risco como mostra a Tabela 1.

Tabela 1: Grau de risco de erodibilidade.

Table 1: Degree of erodibility risk.

\begin{tabular}{c|c|c}
\hline $\begin{array}{c}\text { Baixo Risco } \\
\text { (1 ponto })\end{array}$ & $\begin{array}{c}\text { Médio Risco } \\
\text { (2 pontos) }\end{array}$ & $\begin{array}{c}\text { Alto Risco } \\
\text { (3 pontos) }\end{array}$ \\
\hline Menor que $2 \mathrm{~m}$ & Entre $2 \mathrm{~m} \mathrm{e} 6 \mathrm{~m}$ & Maior que $6 \mathrm{~m}$ \\
\hline
\end{tabular}

Fonte: Adaptado de Correia (2014). Source: Adapted from Correia (2014).

Segundo Cifuentes (1992), o solo classificado com declividade ou aclividade menor que $10 \%$ é considerado baixo ou não é susceptível à erosão, portanto, não são estabelecidas restrições de uso para declividade menor que $2 \mathrm{~m}$. Logo, considera-se apenas o grau médio e alto risco de erosão. Tem-se que Ml = (Médio Risco $\times 2)+($ Alto Risco $\times 3)(\mathrm{m})$ e Mt = comprimento total da trilha $(\mathrm{m})$. A estes fatores, associam-se pontuações de 2 para os de médio risco e de 3 para os de alto risco, de forma a destacar as tendências a erosão. 
Sendo o relevo considerado íngreme, a acessibilidade ao local requer maior esforço físico do visitante. Sendo assim, de acordo com Cifuentes (1992), para o cálculo da acessibilidade deve-se levar em consideração os graus de dificuldade que o visitante tem ao subir e descer a trilha devido ao aclive ou declive. De tal maneira, os graus são classificados na Tabela 2.

Tabela 2: Grau de dificuldade de acessibilidade.

Table 2: Degree of accessibility difficulty.

\begin{tabular}{c|c|c}
\hline $\begin{array}{c}\text { Baixa Dificuldade } \\
\text { (1 ponto) }\end{array}$ & $\begin{array}{c}\text { Média Dificuldade } \\
\text { (2 pontos) }\end{array}$ & $\begin{array}{c}\text { Alta Dificuldade } \\
\text { (3 pontos) }\end{array}$ \\
\hline Menor que $10 \%$ & Entre $10 \%$ e $20 \%$ & Acima de $20 \%$ \\
\hline
\end{tabular}

Fonte: Adaptado de Cifuentes (1992) e Correia (2014).

Source: Adapted from Cifuentes (1992) and Correia (2014).

Analogamente ao FC da erodibilidade, o aclive ou declive menor que $10 \%$ não impõe dificuldade ao visitante, logo não é considerado no cálculo do FC da acessibilidade. Considerando as pontuações para enfatizar as dificuldades no acesso, tem-se que $\mathrm{Ml}=$ (Média Dificuldade $\times 2$ ) $+($ Alta Dificuldade $\times 3$ ) em (m) e Mt = comprimento total da trilha (m).

Em relação aos outros fatores considerados, tem-se que a presença ou ausência de cobertura arbórea influencia na exposição direta ao sol, nas condições de calor intenso e, consequentemente, interfere na preferência do visitante. Ao que se refere à precipitação, a trilha encontra-se em condições instáveis em períodos chuvosos e pode ser interditada. E por fim, considerase o alagamento, já que no período chuvoso trechos da trilha da Gruta do Limoeiro são inundados impossibilitando a passagem de pedestres.

Devido às limitações inerentes a cada um dos cinco fatores, determinaram-se os Fatores de Correção para a obtenção da Capacidade de Carga Real.

\section{Capacidade de Carga Efetiva}

A Capacidade de Carga Efetiva (CCE) é o produto entre a Capacidade de Carga Real (CCR) e da Capacidade de Manejo (CM), sendo que a CM foi obtida da relação entre a Capacidade Adequada e a Capacidade Instalada, as quais correspondem ao que seria necessário ter e ao que atualmente possui, respectivamente. A CCE pode ser obtida então pela fórmula 4:

$$
C C E=C C R * C M(4)
$$




\section{Resultados e discussão}

Considerando o foco do presente estudo, os resultados serão apresentados de acordo com as etapas descritas de acordo com a metodologia proposta.

\section{Capacidade de Carga Física}

A superfície da área visitada foi obtida por meio de cálculos com os dados coletados, resultando em um total de 7.978,503 $\mathrm{m}^{2}$. O espaço ocupado por cada visitante foi definido como $1 \mathrm{~m}^{2}$, sendo que a obra de Cifuentes (1992) ressalta que essa é a área necessária para uma visitante mover-se livremente.

De acordo com informações obtidas no PEML, a unidade possui horário de visitação aos atrativos turísticos de 08 às 16 horas. Considerando um intervalo de tempo de 4 horas levando em conta percurso de ida e volta e interação do visitante com a trilha, obtém-se então que a CCF corresponde a 15.957 visitantes por dia.

\section{Capacidade de Carga Real}

Para o cálculo da Capacidade de Carga, foi necessário considerar os fatores que influenciam na atratividade da trilha. Após o estudo de campo foi possível dimensionar os fatores de erodibilidade $\left(\mathrm{FC}_{1}\right)$, acessibilidade $\left(\mathrm{FC}_{2}\right)$ e cobertura arbórea $\left(\mathrm{FC}_{3}\right)$ por meio das características obtidas na área de estudo. Sendo assim, $\mathrm{FC}_{1}=0,87, \mathrm{FC}_{2}=0,45$ e $\mathrm{FC}_{3}=0,94$.

O período chuvoso foi obtido por meio do estudo de Barbieri e Franchito (20--), que consideraram o período chuvoso da região Sudeste dos meses de outubro a março, com base em análises de estações meteorológicas do período de 1981 a 1996. Portanto, tem-se que $\mathrm{FC}_{4}=0,51$.

O período de alagamento na trilha da Gruta do Limoeiro foi identificado por meio da análise do estudo de Mello e Silva (2009), que verificaram a precipitação anual de Minas Gerais por meio de observações de estações meteorológicas, nas quais o mês de dezembro e janeiro apresentam alto índice de precipitação. Assim, é considerado que a trilha alaga nesse período. Dessa forma, obteve-se o $\mathrm{FC}_{5}=0,84$.

Após a determinação dos cinco Fatores de Correção, calculou-se a Capacidade de Carga Real como 2.515 visitantes por dia.

\section{Capacidade de Carga Efetiva}

A Capacidade de Manejo pode ser calculada com a identificação da infraestrutura, pessoal e manutenção do Parque do Limoeiro e a análise da necessidade de implantação desses, os quais foram estabelecidos obtendo os resultados demonstrados na Tabela 3 . 
Tabela 3: Capacidade de Manejo.

Table 3: Management Capacity.

\begin{tabular}{|c|c|c|c|c|}
\hline \multicolumn{5}{|c|}{ Capacidade de Manejo } \\
\hline Categoria & Variáveis de Manejo & $\begin{array}{l}\text { Capacidade } \\
\text { Adequada }\end{array}$ & $\begin{array}{l}\text { Capacidade } \\
\text { Instalada }\end{array}$ & CM (\%) \\
\hline \multirow{11}{*}{ Infraestrutura } & $\begin{array}{c}\text { Placas de início e fim do } \\
\text { trajeto }\end{array}$ & 2 & 2 & 100 \\
\hline & $\begin{array}{l}\text { Placas de orientação } \\
\text { durante o trajeto }\end{array}$ & 23 & 25 & 92 \\
\hline & Placas interpretativas & 0 & 20 & 0 \\
\hline & Pontes e passarelas & 2 & 4 & 50 \\
\hline & Mirantes & 1 & 5 & 20 \\
\hline & Bancos & 5 & 10 & 50 \\
\hline & Carros para fiscalização & 3 & 5 & 60 \\
\hline & Motos para fiscalização & 1 & 4 & 25 \\
\hline & Prédio Administrativo & 1 & 1 & 100 \\
\hline & Restaurante & 0 & 1 & 0 \\
\hline & Posto Policial Florestal & 0 & 1 & 0 \\
\hline \multirow{3}{*}{ Pessoal } & Gestor & 1 & 1 & 100 \\
\hline & Monitores por dia & 1 & 4 & 25 \\
\hline & Zelador Ambiental & 5 & 8 & 63 \\
\hline \multirow{6}{*}{ Manutenção } & $\begin{array}{c}\text { Capacitação anual de } \\
\text { monitores }\end{array}$ & 0 & 2 & 0 \\
\hline & $\begin{array}{l}\text { Equipamentos de } \\
\text { radiocomunicação }\end{array}$ & 7 & 15 & 47 \\
\hline & $\begin{array}{l}\text { Manutenção geral da } \\
\text { infraestrutura }\end{array}$ & 0 & 6 & 0 \\
\hline & Funcionários de poda & 0 & 5 & 0 \\
\hline & Brigadistas & 6 & 20 & 30 \\
\hline & EPI por funcionário & 1 & 1 & 100 \\
\hline \multicolumn{2}{|r|}{ Média } & 59 & 140 & 42 \\
\hline
\end{tabular}

Fonte: Autores (2016). Source: Authors (2016).

Considerando a Capacidade de Manejo da trilha da Gruta do Limoeiro como 42\%, tem-se que a Capacidade de Carga Efetiva corresponde a 1.056 visitantes por dia.

Os dados encontrados para obter a capacidade de carga da trilha da Gruta do Limoeiro situada no Parque Estadual Mata do Limoeiro encontramse resumidos na Tabela 4.

Como o PEML ainda é uma UC recente, a Capacidade de Carga Efetiva apresenta-se acima da possibilidade de gestão da trilha da Gruta do Limoeiro, dado que o Parque em função de sua extensão possui o corpo de funcionário limitante às diferentes atividades promovidas pelo parque. $\mathrm{O}$ PEML não apresenta ainda um controle efetivo de seus visitantes, bem como as atividades que os mesmos participam, não sendo possível então relacionar a CCE com a média de visitantes por dia. 
Tabela 4: Síntese da capacidade de carga da trilha da Gruta do Limoeiro.

Table 4: Synthesis of the load capacity of the Limoeiro Cave trail.

\begin{tabular}{c|c|c}
\hline \multicolumn{3}{c}{ Capacidade de Carga } \\
\hline CCF & \multicolumn{1}{c}{15.957 visitantes/dia } \\
\hline \multirow{4}{*}{$F$} & $\mathrm{FC}_{1}$ & 0,87 \\
\cline { 2 - 3 } & $\mathrm{FC}_{2}$ & 0,45 \\
\cline { 2 - 3 } & $\mathrm{FC}_{3}$ & 0,94 \\
\cline { 2 - 3 } & $\mathrm{FC}_{4}$ & 0,51 \\
\cline { 2 - 3 } & $\mathrm{FC}_{5}$ & 0,84 \\
\hline CCR & 2.515 visitantes/dia \\
\hline CM & \multicolumn{2}{|c}{0,42} \\
\hline CCE & \multicolumn{2}{|c}{1.056 visitantes/dia } \\
\hline
\end{tabular}

Fonte: Autores (2016). Source: Authors (2016).

No entanto, o resultado da capacidade de carga da trilha pode contribuir para o planejamento do ecoturismo do Parque, de forma a adequar as melhorias ao uso público da área, controlando o número de visitantes da trilha e identificando o perfil destes. É viável que o Parque pondere as atividades de uso público a partir do resultado da capacidade de carga da trilha da Gruta do Limoeiro, bem como incentive estudos dos parâmetros para as demais trilhas, a fim de minimizar os impactos e seus efeitos adjacentes, buscando promover o ecoturismo de maneira sustentável.

Para fins dos estudos foi levado apenas em consideração o limite máximo que a trilha resiste às influências diárias. Ademais, não considera que os visitantes possam causar estresse à fauna e modificações na flora, sendo necessários estudos complementares das espécies e de seu comportamento. Oliveira e outros (2015) citam a importância de ações voltadas na área de educação ambiental para melhor manejo do uso público, de tal forma que o estudo de capacidade de carga também deve estar atrelado a essas ações, visando orientar o uso do Parque.

\section{Conclusões}

A determinação da capacidade de carga é de suma importância para - Parque Estadual Mata do Limoeiro, pois permite que a gestão da UC se adeque aos resultados obtidos às atividades de uso público, em especial a promover o turismo sustentável a partir do acesso às trilhas. A visitação da trilha da Gruta do Limoeiro deve ser feita respeitando o limite de 1.056 visitantes, permitindo que o solo não sofra degradação, nem que hajam impactos relacionados às áreas de borda e estresses na fauna e flora presentes. $O$ resultado caracteriza-se bem acima do fluxo atual de visitantes do PEML, sendo importante para o planejamento de atividades futuras como o ecoturismo. 
Complementar ao estudo de capacidade de carga está a ampliação da educação ambiental, que possibilita ao visitante maiores percepções dos impactos gerados pelo uso das trilhas, no entanto, sem perder o objetivo do turismo sustentável, tratando-se de um processo de aprendizagem e responsabilidade em relação à biodiversidade local. O estudo promove benefícios ao PEML, podendo ser aprofundado, com o intuito de determinar a capacidade de carga de todas as trilhas e consequentemente o número ideal de visitantes por dia de toda a parcela do Parque.

Ressalta-se que 0 turismo sustentável quando manejado corretamente é de suma importância para o contato humano com o meio ambiente, pois proporciona e possibilita a conscientização sobre a preservação dos recursos naturais. Sendo assim, percebe-se que o estudo da capacidade de carga é necessário para que haja um limite do turismo de forma a não prejudicar e impactar os recursos naturais e a biodiversidade, sem perder consequentemente a essência do turismo sustentável.

Diante da importância da capacidade de carga, é necessário que, junto ao período de elaboração do Plano de Manejo de UCs, as mesmas sejam determinadas no Plano de Uso Público, adequando-as à categoria do parque e ao seu limite de visitantes.

\section{Referências}

BARBIERI, P.R.B.; RAO, V. B.; FRANCHITO, S.H. Estudo do Início e Fim da Estação Chuvosa na Região Sudeste do Brasil. [20--]. Disponível em: <www.cbmet.com/cbm-files/22-09bc5b62b286ffa68791a48354c7ae06.doc>.

Acesso em: 25 out. 2016.

BRASIL. Casa Civil. Lei no 9.985, de 18 de julho de 2000. Regulamenta o Art. $225 \S 10$, Incisos I, II, III e VII da Constituição Federal, Institui o Sistema Nacional de Unidades de Conservação da Natureza e dá outras providências. Diário Oficial da República Federativa do Brasil, Brasília, DF, 19 jul. 2000.

CAMPOS, A.M.N. Turismo: a relação do ecoturismo e das trilhas interpretativas. Revista Eletrônica Espaço Acadêmico, Internet, v. nำ 57, 2006.

CIFUENTES, M. Determinación de capacidad de carga turística em áreas protegidas. Bib. Orton IICA/CATIE, 1992. Disponível em: < $<$ https://www.ucm.es/data/cont/media/www/pag-

51898/1992 METODOLOG\%C 3\%8DA\%20CIFUENTES.pdf>. Acesso em: 19 set. 2016.

CORDEIRO, I.D; KÖRÖSSY, N; SELVA, V. Determinação da capacidade de carga turística através do método cifuentes el al. (1992): Aplicação à Praia dos Carneiros (Tamandaré/PE). Revista Turismo Visão e Ação Eletrônica. vol. 15, n.1, p. 57-70, 2013. 
CORREIA, B.H. Trilha do Bolonha: análise da capacidade de carga turística como ferramenta de desenvolvimento turístico e uso racional de espaços públicos naturais em área urbana. Anais do $\mathrm{V}$ Congresso Brasileiro de Gestão Ambiental Belo Horizonte/MG, 2014. Disponível em: <http://www .ibeas.org.br/congresso/Trabalhos2014/XI-094.pdf>. Acesso: 28 out. 2016.

FIGUEIREDO, M.A. et al. Compactação do solo como indicador pedogeomorfológico para erosão em trilhas de unidades de conservação: Estudo de caso no Parque Nacional Serra do Cipó, MG. Revista de Geografia, v. especial, n. 3, set. 2010.

FONSECA FILHO, R.E.; RIBEIRO, G.S. Perfil do geoturista do Parque Estadual da Serra do Rola-Moça (MG). Revista Brasileira de Ecoturismo, São Paulo, v. 9, n. 3, ago/out. 2016, p. 471-496.

GUILLAUNON, J.R. et al. Análise das trilhas de interpretação. São Paulo, Bol. Técn. 25, Instituto Florestal, 1977. 57p.

LEUZINGER, M.D. Uso público em unidades de conservação. Anais do Congresso de Direito Ambiental da PUC-Rio, 1., 2011, Rio de Janeiro. Rio de Janeiro: PUC, 2011. Disponível em: <http://www.nima.pucrio.br/aprodab/artigos/uso publico em unidades de conservacao marcia I euzinger.pdf>. Acesso em: 24 out. 2016.

LOBO, H.A.S. Ecoturismo e percepção de impactos socioambientais sob a ótica dos turistas no Parque Estadual Turístico do Alto Ribeira-PETAR. Pesquisas em Turismo e Paisagens Cársticas, v. 1, n. 1, p. 67-75, 2008.

MELLO, C.R.; SILVA, A.M. Modelagem estatística da precipitação mensal e anual e no período seco para o estado de Minas Gerais. Revista Brasileira de Engenharia Agrícola e Ambiental. v.13, n.1, p.68-74, 2009.

MENGHINI, F.B.; GUERRA, A.F.S. Trilhas interpretativas: caminhos para a educação ambiental. Anais do VII Seminário de Pesquisa em Educação da Região Sul. 2008, Itajaí: Univali. Disponível em: $<$ http://www.portalanpedsul.com.br/admin/uploads/2008/Educacao ambienta I/Trabalho/05 0812 Trilhas interpretativas caminhos para a educacao ambiental.pdf>. Acesso em: 19 out. 2016.

MINAS GERAIS. Decreto no 45.566, de 22 de março de 2011. Cria o Parque Estadual Mata do Limoeiro, localizado no Município de Itabira, e dá outras providências. Diário do Executivo de Minas Gerais. Belo Horizonte, MG, $2011 . \quad$ Disponível em: $<$ http://www.siam.mg.gov.br/sla/download.pdf?idNorma=16514 >. Acesso em: 25 out, 2016.

NELSON, S.P. Uso Público nas Unidades de Conservação. In: CASES, M.O. (Org.). Gestão de Unidades de Conservação: compartilhando uma experiência de capacitação. Brasília: Áttema Editorial, 2012. 396p.

OLIVEIRA, A.C. et al. Educação ambiental em unidades de conservação: o caso do Parque Estadual Mata do Limoeiro, Itabira/MG. Anais do $28^{\circ}$ Congresso Brasileiro de Engenharia Sanitária e Ambiental, 2015, Rio de Janeiro/RJ. ABES, 2015. 
PEML. PARQUE ESTADUAL MATA DO LIMOEIRO (Org.). Plano de Manejo do Parque Estadual Mata do Limoeiro: Encarte 1 - Análise Geoambiental. Belo Horizonte: Bicho do Mato, 2012. 556 p. Disponibilizado pelo gestor da unidade.

PONTES, J.A.L.; MELLO, F.A.P. Uso público em unidades de conservação de proteção integral: considerações sobre impactos na biodiversidade. Anais do Uso público em unidades de conservação n. 1, p. 221-232. Disponível em: $<$ http://www.uff.br/var/www/htdocs/usopublico/images/Artigos/2013/Artigo O L 22.pdf>. Acesso em: 25 out. 2016.

SILVA, A.N. et al. Unidades de conservação da natureza. São Paulo: SMA, 2009. 104 p. ISBN 978-85-86624-60-5. Disponível em: $<$ http://www.ambiente.sp.gov.br/wp-

content/uploads/publicacoes/sma/unidConservNat.pdf>. Acesso em: 25 out. 2016.

SOUZA, P.C.; MARTOS, H.L. Estudo do uso público e análise ambiental das trilhas em uma unidade de conservação de uso sustentável: Floresta Nacional de Ipanema, Iperó - SP. Rev. Árvore, Viçosa, v. 32, n. 1, p. 91100, Fev. 2008.

SWARBROOKE, J. Sustainable Tourism Management. Cabi Publishing: New York, 1999. Disponível em: $<$ https://www.cpp.edu/ ddwills/SCHOTO\%20Workshop/STM.PDF>. Acesso em: 19 out. 2016.

TAKAHASHI, L.Y. Uso público em unidades de conservação. Cadernos de Conservação: ano 2. n. 2. Curitiba - PR. Fundação O Boticário de Proteção da Natureza, 2004.

VIANA, F.M.F. Análise ambiental da capacidade de carga antrópica nas trilhas do circuito janela do céu - Parque Estadual do Ibitipoca, MG. Monografia da Especialização (Conclusão de curso). 2008. Universidade Federal de Juiz de Fora, Faculdade de Engenharia, Juiz de Fora. 
Amanda Costa de Oliveira: Universidade Federal de Itajubá, Itabira, MG, Brasil.

E-mail: amandacoliveira95@gmail.com

Link para o currículo Lattes: http://lattes.cnpq.br/7768121712551188

Ana Cecília Gomes de Paula: Universidade Federal de Itajubá, Itabira, MG, Brasil.

E-mail: ana-cecilia-gp@hotmail.com

Link para o currículo Lattes: http://lattes.cnpq.br/0567446369602804

Clarisse Carvalho Miranda: Universidade Federal de Itajubá, Itabira, MG, Brasil.

E-mail: clarissecarvalho.m@gmail.com

Link para o currículo Lattes: http://lattes.cnpq.br/8217759877985364

Gabriel Henrique Soares Almeida: Universidade Federal de Viçosa, Viçosa, MG, Brasil.

E-mail: gabriel.h.almeida@ufv.br

Link para o currículo Lattes: http://lattes.cnpq.br/0450032475529268

Edson Maurício Marques Ferrari: Universidade Federal de Itajubá, Itabira, MG, Brasil.

E-mail: ferrari.ambiental@hotmail.com

Link para o currículo Lattes: http://lattes.cnpq.br/8970449244306336

Bianca Cabral Caldeira: Universidade Federal de Itajubá, Itabira, MG, Brasil.

E-mail: biancaunifei@gmail.com

Link para o currículo Lattes: http://lattes.cnpq.br/9894812948681371

Data de submissão: 31 de outubro de 2016

Data de recebimento de correções: 21 de setembro de 2017

Data do aceite: 21 de setembro de 2017

Avaliado anonimamente 